\title{
AUGMENTED REALITY AS A TEACHING TOOL IN HIGHER EDUCATION
}

\author{
Dr. Tashko Rizov, University “Ss. Cyril and Methodius”, Faculty of Mechanical Engineering, Skopje, \\ Republic of Macedonia, E-mail: tashko.rizov@mf.edu.mk \\ Dr. Elena Rizova, University “Ss. Cyril and Methodius”, Faculty of philosophy, Skopje, \\ Republic of Macedonia, E-mail: elenarizova@fzf.ukim.edu.mk
}

Received: May, 14.2015. Accepted: June, 01.2015. Original Article

UDK 004:378.147

\begin{abstract}
Rapid development of the technology has influenced its inevitable entrance in the learning processes. Teachers are often challenged to use the appropriate educational technology in the process of teaching in order to ease the learning process of students. Introducing new technology in the teaching process should utilize the new technology in any possible way in order to assist the teacher in transferring the knowledge and assist the students in grasping that knowledge. This paper should emphasize the benefits of using augmented reality in higher education, by measuring outcomes of the students which used augmented reality as a teaching tool in the courses. Results from the survey imply that students show significantly improved results in increasing the interest, understanding and interiorizing the learning material. University teachers found that using augmented reality is significantly improving the learning process of students and their teaching process in a pedagogical and technical sense.
\end{abstract}

Keywords: Augmented reality, Teaching techniques, Modernization.

\section{INTRODUCTION}

Today's Europe is facing serious changes which are equal by their significance to the industrial revolution. Rapid growth of the technology is influencing changes in everyday life of the people. Processes of globalization are widening societal horizons and causing economic competitiveness. The only way to survive in the contemporary societies and to sustain economic competitiveness is active participation in lifelong learning process, by upgrading current competences and obtaining new competences, needed in the labor market.

Corresponding Author

Dr. Elena Rizova, University "Ss. Cyril and Methodius", Faculty of philosophy, Skopje, Republic of Macedonia, E-mail: elenarizova@fzf.ukim.edu.mk
Representatives of the modern pedagogy for the last five decades are emphasizing the fact that education needs transformation in order to meet the demands of the contemporary living (European Commission, 2000). It is wrong to think that technology which has entered in all of the spheres of everyday life should be excluded from the process of education. Today, we are still facing with students resistance and indifference to learn by old, ex-cathedra methods of teaching. Modern students are digital natives which use technology in their everyday activities, while education has kept the tendency to treat the students as an object in the teaching process, without any active role - which is contradictory to the main objective of the lifelong learning process (European Commission, 2011).

In the Memorandum for lifelong learning (2000) issued by European Commission, the third key message of the document, is referring to Innovation in teaching and learning. Teaching and learning methods and contexts should recognise and adapt to a highly diverse range of interests, needs and demands of the people. Enabling individuals to become active learners implies both improving existing practices and developing new and varied approaches to take advantage of the opportunities offered by ICT and by the full range of learning contexts. ICT-based learning technologies offer great potential for innovation in teaching and learning methods, although practicing educationalists insist that, to be fully effective, these must be embedded in 'real time' contexts and relationships between teachers and learners. The capacity and the confidence to develop and practice open and participatory teaching and learning methods should therefore become an essential professional skill for educators and trainers, in both formal and 
non-formal settings (Memorandum for lifelong learning (2000)).

Europe's and worlds educational systems are allowing the technology to take big part in the process of teaching and learning by offering different types of learning: distance and e-learning, video, television and web conferences, webinars, corresponsive teaching, etc. Republic of Macedonia is facing those challenges as well, and as if from recently has obligated teachers from elementary and secondary schools to use educational technology with at least $30 \%$ in their teaching (Ministry for education and science of Republic of Macedonia, 2006).

\section{USING AUGMENTED REALITY AS A TEACHING TOOL}

According to Azuma (1997), Augmented Reality (AR) is a variation of Virtual Environments (VE), or Virtual Reality as it is more commonly called. In these so called Virtual Environments the user is completely surrounded by a synthetic environment. In that state, the user can not perceive the real world and the real environment that surrounds him/her. On the contrary, the Augmented Reality (AR) allows the user to perceive the real world while the virtual elements are superimposed upon or composited with the real world (Sutherland, 1968). In this manner, the augmented reality is enriching user's perception of the reality rather than totally replacing it like in the case of the virtual environments. The ultimate goal of the AR is to convince the user that the two environments, real and virtual, coexist. According to Azuma (Azuma, 1997) augmented reality presents a system with the following characteristics: (1) combines real and virtual world, (2) interactive in real time and (3) registered in 3D (Azuma, 1997). In that regard, the AR improves our perception of the reality and the real world that is around us, and in the same time it enhances the way we interact with it. The idea behind the technology is to present the user with the ability to perceive information that using the normal natural senses are not directly detectable. Still, the enhancement of the user's reality should help the user in completing regular real-world tasks and activities.

The technology of Augmented Reality can be used to augment all of the user senses, although the vast majority of applications are focused only to the sight by combining virtual graphics with the reality the users sees. There are available researches and application of haptic devices that augment the tactile sense of the user, while the augmentation of sound and smell are still limited.

In this paper the focus is only on vision as most important aspect in learning and education. By augmenting the student's vision we enhance their ability to visualize what they are trying to learn.

When creating an AR system the basic dilemma is how to achieve the needed mix of reality and virtual objects. Basically, two options are available: optical and video technologies. Each has particular advantages and disadvantages (Wagner, Schmalstieg, 2007). By using standard Head-Mounted Displays (HMD) an augmentation of the vision is easily achieved. The standard opaque HMD do not allow a direct view to the real environment because they use video technologies where both the real and virtual images are presented as video signals. On the other hand, see-through HMDs enable the user to visually perceive reality that surrounds, complemented with virtual objects designed using optical or video technology. The optical see-through HMD operate by having laid optical devices for combining sight of the user with the virtual video objects in front of the user's eyes. These combining devices are partially transparent, thus the user is able to see straight through them, looking at the real world. These combining devices are partially reflective, thus the user is able to see virtual images that are reflected by them. This approach is similar to the technology of the Head-Up Displays (HUD). Therefore, optical see-through HMD devices are sometimes described as "HUD mounted on the user's head". HUD devices were first used by the pilots of fighter jets, with that difference that in those cases the combining devices were placed on the protective glass of the cabin of the aircraft rather than on the user's head. HUD devices today have a massive application in the automotive industry. During 2013, out of 87.5 million vehicles produced in the world, one million vehicles have built in HUD device. According to PR Newswire, in the US, by the end of 2018 the total market for HUD devices will rise three times.

The only way to determine if an AR system is satisfactory is through the level of realism in the integration of augmentations and the reality. In order to achieve this set of challenges has to be resolved. The main challenges when using AR are focus, contrast, registration and occlusion. The challenge of determining the right focus is present in both 
optical and video AR systems. When combining two video signals a common problem is combining the focus settings using the depthof-field and the focus settings of the pine-hole model. This challenge can be overcome by using cameras with auto focus options and by rendering graphic objects simulating a limited depth-of-field (Yeh, Wickens, 2001). When using optical technology, the challenge of focus errors result from the fact that real object are at different distances from the user and the virtual object are always presented at a fixed distance. If these distances are not aligned with the distances of the same objects in reality, than the augmentation will be out of focus or blurred.

The challenge of contrast is to match correctly the brightness of both virtual and real objects. Although this seems as an easy task, the challenge comes from the fact that the human eye is able to differentiate very large levels of brightness. This challenge is more present in optical devices, while in the video devices this challenge is easily solvable (Cobzas, Jagersand, 2003).

Registration presents the proper alignment of the virtual and real objects in regard to their interrelation and in regard to the surrounding environment. Registration provides the key element of persuading the user that both worlds coexist in the same space and time. In addition, the specific properties of the application of the AR demand different levels of precision in registration. For example in medicine and in engineering the levels of precision are highest and it is fundamental for the proper use of the technology. According to Breen (Breen et al., 1996), errors in registration are difficult to properly control because of the high accuracy requirements and the numerous sources of error.

Occlusion is the overlapping of virtual and real objects in the AR systems. The system should properly align and overlap the virtual and real object as the user's perception of their coexistence in reality. This is present in both video and optical AR systems. With the use of cameras determining depth or by properly preparing the scene this challenge can be resolved.

\subsection{Teaching engineering graphics}

For the purposes of the research, regarding the nature of the provision of one semester courses at university level, we found it most appropriate to test augmented reality as a teaching tool among students and university teachers from the technical faculties from the biggest state university in Republic of Macedonia - "Ss. Cyril and Methodius" in Skopje within the courses in technical drawing, engineering geometry and graphics. This course called Engineering graphics is mandatory for almost every technical faculty at the private and state universities in the country because it represents foundation for engineering profession.

Among other theoretical topics which are processed in the course, practical exercises from all areas of geometry and engineering graphics are performed using a software tool for computer-aided design (CAD).

During the practical exercises, one of the key challenges for the teacher is to find out a way to assist the students in the process of visualization of objects presented in different spaces and shapes. A common task in this manner is for a specific shape given by two orthogonal projections to be visualized as a solid body.

\section{$35 \mathrm{C}$}

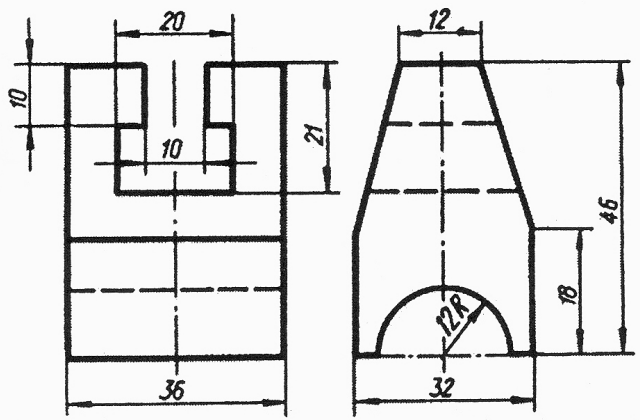

Picture 1. Example of a student's exercise - the task is to create a solid body out of two given orthogonal projections

When this task is to be completed for a simple shape, than best way to assist the students in the process of visualization of object is by using wooden or plastic models. Still, this method is slow, time demanding and costly. Also, it is not suitable for larger groups of students since the result cannot be displayed using a LCD projector. Even though university teachers attempt to make this process as simple as possible by using the best existing didactic methods it is very common that number of students lose interest and become repulsive to the subject. As most common reason for this is the fact that majority of the students come from general high schools, only small portion of them have graduated from technical vocational schools. This means that most of them get in contact with geometrical shapes 
and bodies in space for the first time.

A constant strive of all teachers is to keep the attention of the students and their interest as much as possible. In order to do this, teachers must introduce innovative ways of executing the classes. In this digital day and age it is inevitable to turn towards ICT technologies to achieve this goal - that is assist students in understanding the space and how objects are placed in it. In this regard, the used tools are focusing on the visual presentation of the matter. In the end, this has to be done in an efficient and effective manner for both the teacher and the students.

The properties of augmented reality presented earlier in this paper are in line with these needs. An application designed on the basis of the AR technology can provide the teacher with the ability to visually present to the students a three-dimensional shape created out of its two orthogonal projections presented in the textbook.

There are various off-the-shelf software tools available for creating the AR application for this problem. They differ in the needed computer skills of the creator, as well as in the platform on which they can operate (Windows, Android or iOS). With that, the boundary of the devices used to create and utilize the application is no more present, meaning one can use a desktop computer, or a hand-held device like a smartphone or tablet. The system architecture is usually consisted of a computational device, digital camera and the desired software for previewing the result.

The solution can be created to be used in a prepared or unprepared scene. If the application is to be used in an unprepared scene than additional hardware devices for determining and tracking the position are needed, like gyroscopes, GPS receivers, compass etc. Still, such an application is mainly meant to be used in a classroom which means the prepared scene option is a better choice. In these cases the determination of the position and tracking is done using fiducial markers. Besides the determination of position ant tracking, the marker is going to solve the challenges regarding registration and occlusion and it will provide the means of interaction between the users and the application. Best way is to use a robust black and white marker with characteristic shape (square or circle). This is determined by the software architecture algorithm for detection and tracking. The marker will be used as a trigger element, once induced in the camera's field of view it will trigger the system to recall the appropriate virtual object.
The final elements of the application are the virtual objects. They have to be created and stored in a database accordingly and mapped with a corresponding marker. The virtual objects can be 3D models, text, image or video (Rizov, Tashevski, 2015). For the purpose of this paper, 3D solid models were created using Autodesk AutoCAD and a corresponding animation of the 3D model was created using Autodesk 3D Studio.

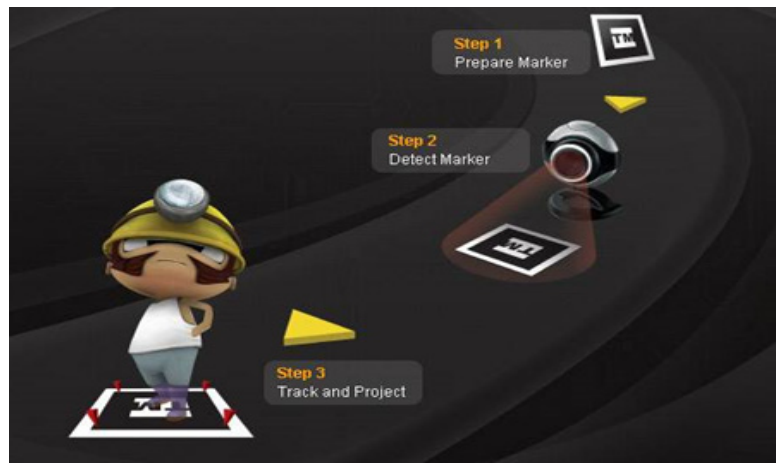

Picture 2. The basic steps of augmented reality using markers

The augmentation of the reality happens according the diagram presented in Picture 2. Firstly the markers are prepared, than they are introduced into the field of view of the camera and after that the algorithm detects and follows the marker with superimposing the appropriate virtual element on it. As the user manipulates the marker the virtual element corresponds. The virtual element can be presented directly in the same plane as the marker or it can be projected at an offset from the marker. The camera in this diagram presents an input device. It may be an external hardware element, as the web cam to a desktop, or it can be integrated in the device, like the camera on a smartphone.

In this paper, the software application BuildAR of HITLAB with the ARToolKItPlus algorithm was used. This application is for windows environment only, but it presents an all-in-one solution, meaning the user can create the markers, create the AR scene, can edit it and can preview it. Also its algorithm is most suitable for squared black and white markers and provides easy and precise tracking while rotation and translation of the marker. 


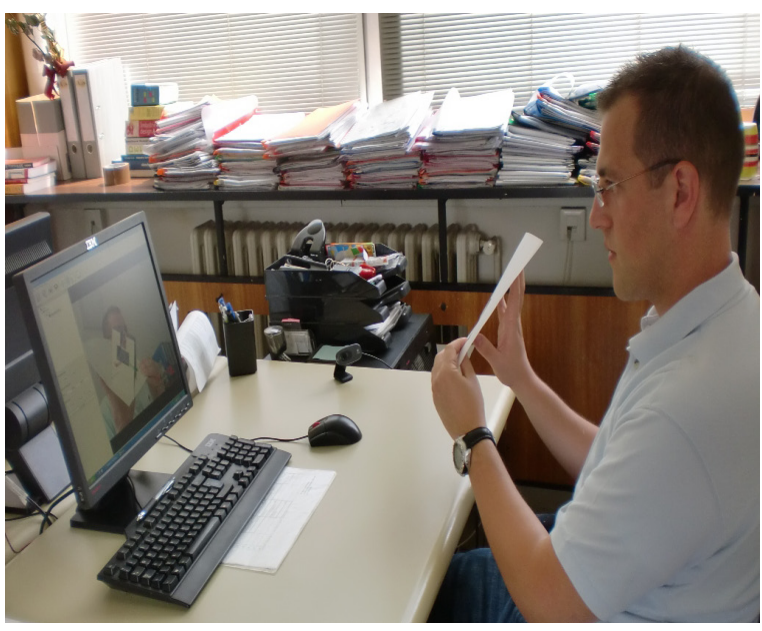

Picture 3. Displayed video signal from the camera

As mentioned previously, for the purpose of this research, the student's exercise presented in picture 1 is going to be used as given orthogonal projections out of which students need to create a $3 \mathrm{D}$ solid model. After starting the application on their desktop computer, students select the available video capturing device and in the field of view of the camera introduce the marker corresponding to the given exercise. After that the software detects the marker, identifies the corresponding 3D model from the database and recalls it.

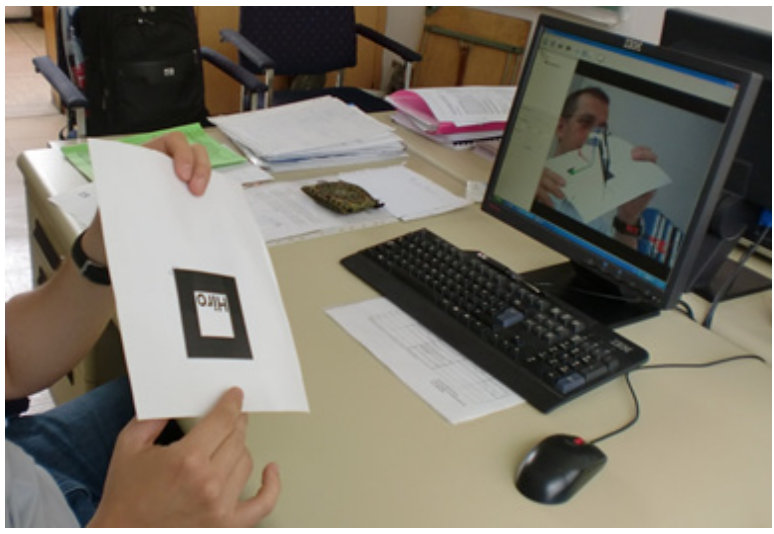

Picture 4. Introducing marker to the camera's field of view

Then the software renders the 3D model over the marker, making it visible to the user. In this way the user's reality is augmented. The interaction between the user and the system is through movement of the marker. Students can move the marker or rotate it so they can see the solid object from all sides and angles.
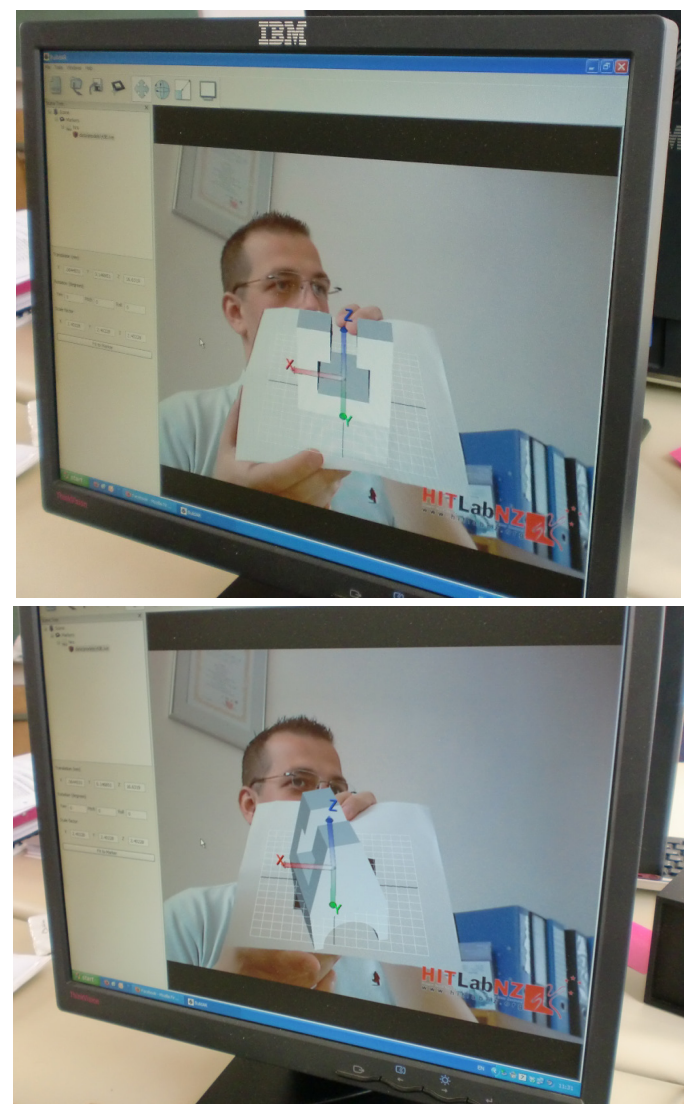

Picture 5. Preview of the result of the shape in augmented reality

\section{MATERIALS AND METHODS}

The main goal of the research is to examine whether augmented reality used as a teaching tool is contributing towards improving the interest, understanding and interiorization of the learning material in the course Engineering graphics at higher education.

The character of the research is empirical and quantitative, because it is based on results from the test from the students, as well as from results gained from the questionnaires about student's and university teacher's opinions about the strengths, weaknesses and threats from using augmented reality as a teaching tool in higher education. It is also current, because it is treating the most actual theme in education - using ICT in the teaching process. The research may be considered as action research also, because it's revealing the ongoing changing situation of student's success in the course Graphic engineering in higher education.

This research implies using several research methods, which led to creating scientific conclusions: method of description, analysis, synthesis, induction, and generalization. 
Research techniques and instruments used in order to obtain relevant data are:

- Testing of skills for orthogonal projections of a solid body from 2D to 3D (see picture 1) using test of skills with AutoCAD software on computer;

- Inquiring, using questionnaire from Likert type in order to found out the opinions of students and university teachers about the strengths, weaknesses and threats from using augmented reality as a teaching tool in the course graphic engineering. The questionnaire for students is consisted of 3 parts. The first part is referring to the strengths of augmented reality and is consisted out of 7 statements. The second part of the questionnaire is consisted with 7 statements referring to the weaknesses of using augmented reality in the teaching process and the third part of the questionnaire with 6 statements, refers to the possible threats of using augmented reality in higher education. Students opinions are expressed by demonstrating their acceptance or denial of the statements with gradation of opinions (1-highly agreed till 5-highly disagree with the statement). The questionnaire for university teachers is consisted out of three parts also. The first and the second part are consisted of 7 statements and are referring to found out the strengths and the weaknesses of using augmented reality as a teaching tool, and the third part, consisted of 6 statements is referred to the possible threats of using augmented reality.

In the sample of the research participated 321 students and 12 university teachers from the following technical faculties of the "University Ss. Cyril and Methodius" in Skopje: Faculty of mechanical engineering, Faculty of civil engineering, Faculty of Electrical engineering and information technologies, Faculty of architecture, Faculty of technology and metallurgy, and Faculty of design and technologies of furniture and interior. Distribution of the sample is listed below:

- A sample of students from the Faculty of mechanical engineering - Skopje $(\mathrm{N}=96)$ and a sample of university teachers from the same faculty $(\mathrm{N}=2)$.

- A sample of students from the Faculty of civil engineering - Skopje $(\mathrm{N}=68)$ and a sample of university teachers from the same faculty $(\mathrm{N}=2)$.

- A sample of students from the Faculty of Electrical engineering and information technologies - Skopje $(\mathrm{N}=62)$ and a sample of university teachers from the same faculty $(\mathrm{N}=2)$.

- A sample of students from the Faculty of architecture - Skopje $(\mathrm{N}=43)$ and a sample of university teachers from the same faculty $(\mathrm{N}=2)$.

- A sample of students from the Faculty of technology and metallurgy - Skopje $(\mathrm{N}=29)$ and a sample of university teachers from the same faculty $(\mathrm{N}=2)$.

- A sample of students from the Faculty of design and technologies of furniture and interior - Skopje $(\mathrm{N}=23)$ and a sample of university teachers from the same faculty $(\mathrm{N}=2)$.

\section{RESULTS AND DISCUSSIONS}

The methodology of the research implies taking several action research steps in order to obtain the final results and conclusions. Statistical procedures which were undertaken for processing the results included: numerical and percentage distribution of results, finding the mode (the most frequent opinion) and chi square to found out about the differences in opinions among students and university teachers from different faculties.

Results obtained from the skills test from the course Engineering graphics which intension was to measure the initial state of the students success in passing the test, before implementation of augmented reality, shows partial understanding of the learning material.

Namely, $62 \%$ of the students successfully pass the test. $28 \%$ from them pass the test with high grade, $19 \%$ with average grade and $15 \%$ with below average grade.

\section{Student's success of initial skills test in Engineering graphics}

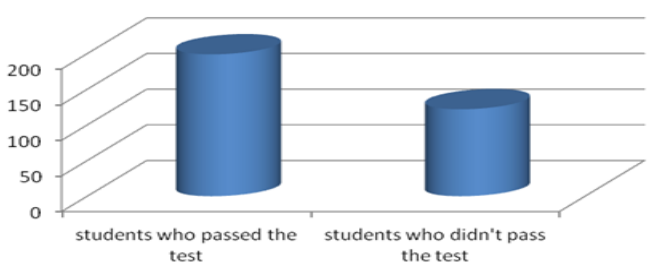

Graph 1. Students' frequency presentation about success of initial skills test in Engineering graphic

It is interesting to notice that to the questions related to the skills for projection of bodies in space, more than half of the students show below average results. That is pointing out towards the problems they have for understanding and interiorizing this complex problematic. All of the stated is an additional 
proof for the need of change in the didactic realization of the learning material, especially in the practical exercises of the course.

The results from the final knowledge and skills test, conducted after implementation of augmented reality as a teaching tool, show a positive trend in student's accomplishments. More than two thirds of the students $(84 \%)$ pass the test: $47 \%$ of them with high grade, $28 \%$ with average grade and only $9 \%$ with bellow average grade.

\section{Student's success of final skills test in Engineering graphics}

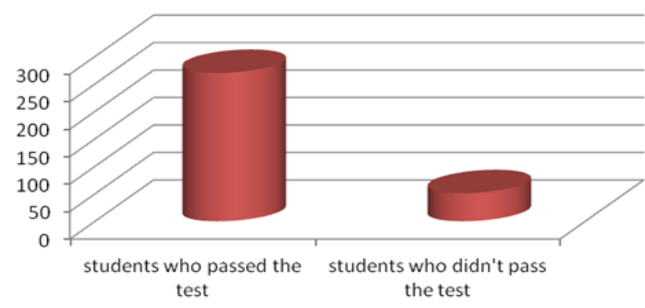

Graph 2. Students' frequency presentation about success of final skills test in Engineering graphic

\section{Student's success of final skills test in Engineering graphics by grades}

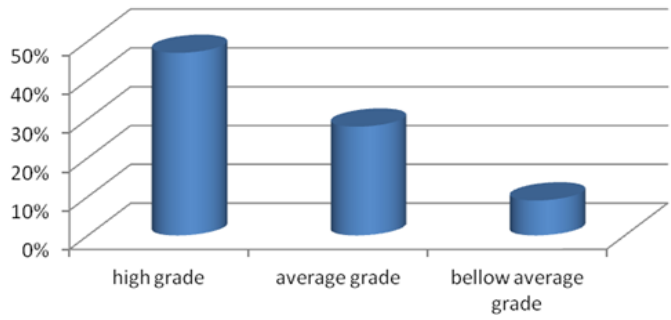

Graph 3. Students' percentage presentation about success of final skills test in Engineering graphic by grades

These results are showing that significant growth of student's accomplishments, especially that almost half of them show high results as a consequence from implementing augmented reality as a teaching tool in the course.

Results from the questionnaire intended to found out student's opinions of augmented reality's strengths, weaknesses and threats show that students are thrilled working with this technology in the course. Almost every one $(96 \%)$ of the interviewed students stated that this kind of lectures are more interesting for them, they are contributing towards better understanding of the material $(100 \%)$ and can eventually lead to passing the course $(68 \%)$.
Table 1. Results of the student's opinions from the statement: Lectures using augmented reality are very interesting for me

\begin{tabular}{lrr}
\hline $\begin{array}{l}\text { Statement: Lectures using augmented } \\
\text { reality are very interesting for me }\end{array}$ & \multicolumn{1}{c}{ f } & \multicolumn{1}{c}{$\%$} \\
\hline Highly agree & 280 & 87,23 \\
\hline Partially agree & 29 & 9,03 \\
\hline Neutral & 0 & 0 \\
\hline Partially disagree & 0 & 0 \\
\hline Highly disagree & 0 & 0 \\
\hline TOTAL & 321 & 96,26 \\
\hline
\end{tabular}

Table 2. Results of the student's opinions from the statement: Augmented reality is contributing towards better understanding of the learning material

\begin{tabular}{lrr}
\hline $\begin{array}{l}\text { Statement: Augmented reality is } \\
\text { contributing towards better } \\
\text { understanding of the learning material }\end{array}$ & f & \multicolumn{1}{c}{$\%$} \\
\hline Highly agree & 296 & 92,21 \\
\hline Partially agree & 25 & 7,79 \\
\hline Neutral & 0 & 0 \\
\hline Partially disagree & 0 & 0 \\
\hline Highly disagree & 0 & 0 \\
\hline TOTAL & 321 & 100 \\
\hline
\end{tabular}

Table 3. Results of the student's opinions from the statement: Using augmented reality as a teaching tool is eventually leading towards passing the course

\begin{tabular}{lrr}
\hline $\begin{array}{l}\text { Statement: Using augmented reality as } \\
\text { a teaching tool is eventually leading } \\
\text { towards passing the course }\end{array}$ & f & $\%$ \\
\hline Highly agree & 142 & 44,24 \\
\hline Partially agree & 76 & 23,68 \\
\hline Neutral & 52 & 16,20 \\
\hline Partially disagree & 36 & 11,21 \\
\hline Highly disagree & 15 & 4,67 \\
\hline TOTAL & 321 & 100 \\
\hline
\end{tabular}

While the benefits for the teachers from implementation of augmented reality as a teaching tool are summarized trough their statements opinions that: Implementation of augmented reality is contributing towards saving time in lecturing $(76 \%)$; It is a pleasure implementing sophisticated teaching methods $(65 \%)$ and that Student's show increased interest for the learning material $(87 \%)$. Students and university teachers both agreed that it is most likely that augmented reality can be interdisciplinary implemented, and see its implementation in different areas like: medicine, education, design, architecture, etc. 


\section{Implementation of augmented reality is contributing towards saving time in lecturing}

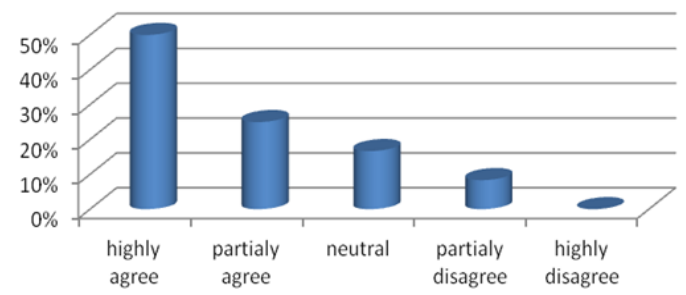

Graph 4. University teachers' opinions about the statement: Implementation of augmented reality is contributing towards saving time in lecturing

Table 4. Chi-square calculation of the statement: Augmented reality is applicable on other areas of study

\begin{tabular}{lccccccc}
\hline & Opinion & $\begin{array}{c}\text { Totally } \\
\text { agree } \\
\text { Faculty }\end{array}$ & $\begin{array}{c}\text { Partially } \\
\text { agree } \\
\text { (f) }\end{array}$ & Neutral & $\begin{array}{c}\text { Partially } \\
\text { disagree } \\
\text { (f) }\end{array}$ & $\begin{array}{c}\text { Totally } \\
\text { disagree } \\
\text { (f) }\end{array}$ & $\begin{array}{c}\text { Total } \\
\text { (f) }\end{array}$ \\
\hline $\begin{array}{l}\text { Faculty of mechanical } \\
\text { engineering }\end{array}$ & 61 & 17 & 13 & 4 & 1 & 96 \\
\hline Faculty of civil engineering & 48 & 9 & 7 & 2 & 2 & 68 \\
\hline Faculty of electrical engineering & 37 & 16 & 5 & 2 & 2 & 62 \\
\hline Faculty of architecture & 33 & 7 & 2 & 1 & 0 & 43 \\
\hline $\begin{array}{l}\text { Faculty of technology and } \\
\text { metallurgy }\end{array}$ & 22 & 5 & 1 & 1 & 0 & 29 \\
\hline $\begin{array}{l}\text { Faculty of design and } \\
\text { technologies of furniture and } \\
\text { interior }\end{array}$ & 22 & 1 & 0 & 0 & 0 & 23 \\
\hline Total (f) & 223 & 55 & 28 & 10 & 5 & 321 \\
\hline \multicolumn{1}{c}{$\chi^{2}=22,68 \quad \mathrm{df}=20$} & $\mathrm{p}$ o.05=31,410 & $\mathrm{p} 0.01=37,566$ & $\mathrm{p}>0.05$ & \\
\hline
\end{tabular}

From the results projected in Table 4, we can conclude that there is no meaningful statistical difference between students' from different faculties' opinions. That is leading us to conclusion that more than two thirds of the students agree that augmented reality is applicable on other areas of study.

The weaknesses, or possible threats that teachers stated regarding implementation and realization of the course Engineering graph$i c s$ are referring to the deficiency of licensed software for augmented reality at the university level, and not enough equipment of the university classrooms with personal computers with cameras which will slow down the process of learning.

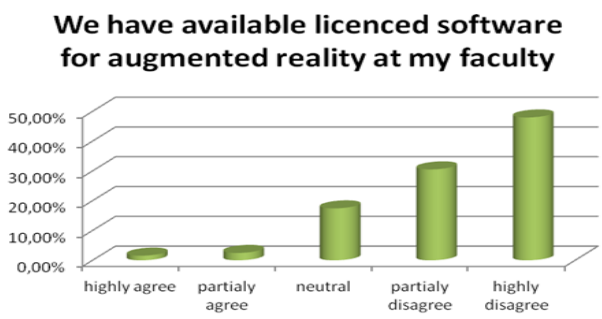

Graph 5. Students' opinions about the statement: We have available licensed software for augmented reality at my faculty

\section{CONCLUSION}

This paper presents how augmented reality can be applied in the education process as a didactic tool in executing classes in higher education. With its use the teachers and the educational institutions can sustain the students' attention and interest to the course while in the same time facilitates the learning process. The achieved results in the pilot use of the application as a teaching tool at the technical faculties showed remarkable results. The application helps the teacher to present the objects in space with adequate visualization. On the other hand, the idea of using new technologies which represent the everyday life of this generation aids in keeping the students' interest. The ability for physical interaction with the application is providing them additional assistance in exploring the geometry of shapes in space. This application is only a showcase presenting a mode of use in technical education, but its customization to other educational areas is very easy, like its use in medicine or design is also very attractive.

The application achieved results in shortening 
the needed time of the student to understand and interiorize the learning material, which in the end results with successful passing the courses. At the same time, this application is assisting the teachers in easier transfer of knowledge for the given course.

\section{Conflict of interests}

Authors declare no conflict of interest.

\section{REFERENCES}

Azuma, R. T. (1997). A survey of augmented reality. Presence, 6(4), 355-385.

Breen, D. E., Whitaker, R. T., Rose, E., \& Tuceryan, M. (1996). Interactive occlusion and automatic object placement for augmented reality. In Computer Graphics Forum 15(3), pp. 11-22. Blackwell Science Ltd.

Cobzas, D., \& Jagersand, M. (2003). A comparison of viewing geometries for augmented reality. In Image Analysis (pp. 501-508). Springer Berlin Heidelberg.

EDUCAUSE Learning Initiative (2005). 7 Things You Should Know About Augmented Reality. EDUCAUSE Learning Initiative.

EU Commission (2000). Memorandum on lifelong learning. Bruxelles: EU.

EU Commission (2011). Council Resolution on a Renewed Agenda for adult learning. Bruxelles: EU.

Jarvis, P. (Ed.) (2001). The age of learning: education and the knowledge society. Psychology Press.

Ministry for education and science of Republic of Macedonia (2006). National program for development of education in Republic of Macedonia 2005-2015, Skopje: Ministry for education and science of Republic of Macedonia.

Rizov T. \& Tashevski R. (2015). Advanced Visualization Technologies as a Tool for Identification of Vehicle Data Details and Elements; XXV International Automotive Conference - Science and Motor Vehicles; Belgrade, Serbia.

Rizov, T. \& Tashevski, R. (2013). Geo-based systems in augmented reality. Mechanical Engineering Scientific Journal; Faculty of Mechanical Engineering - Skopje, 31(1-2), 30-34.

Sutherland, I. E. (1968). A head-mounted three dimensional display. In Proceedings of the December 9-11, 1968, fall joint computer conference, part $I$ (pp. 757-764). ACM.

UNESCO, (1995). World Education Report, Oxford: UNESCO Publishing.

Wagner, D. \& Barakonyi, I. (2003). Augmented reality kanji learning. In Proceedings of the 2nd IEEE/ ACM International Symposium on Mixed and Augmented Reality (p. 335). IEEE Computer Society.

Wagner, D. \& Schmalstieg, D. (2007). Artoolkitplus for pose tracking on mobile devices (pp. 139-146). na. Proceedings of 12th Computer Vision Winter Workshop (CVWW'07), Austria.

Yeh, M. \& Wickens, C. D. (2001). Display signaling in augmented reality: Effects of cue reliability and image realism on attention allocation and trust calibration. Human Factors: The Journal of the Human Factors and Ergonomics Society, 43(3), 355-365. 
(IJCRSEE) International Journal of Cognitive Research in Science, Engineering and Education Vol. 3, No.1, 2015. 